\title{
Toxicological Effects of Organophosphates Pesticides
}

\author{
Mohamed A. Ghorab ${ }^{1}$, Mohamed S. Khalil ${ }^{2}$ \\ ${ }^{1}$ National Institute of Oceanography and Fisheries (NIOF), Environmental Toxicology Laboratory, Central Laboratories Unit (CLU), \\ Alexandria, Egypt \\ ${ }^{2}$ Agriculture Research Center (ARC), Central Agricultural Pesticides Laboratory (CAPL), El-Sabaheya, Alexandria, Egypt
}

Email address:

mghorabniof@gmail.com (M. A. Ghorab),m_salah2511@yahoo.com (M. S. Khalil)

\section{To cite this article:}

Mohamed A. Ghorab, Mohamed S. Khalil. Toxicological Effects of Organophosphates Pesticides. International Journal of Environmental Monitoring and Analysis. Vol. 3, No. 4, 2015, pp. 218-220. doi: 10.11648/j.ijema.20150304.13

\begin{abstract}
For many years organophosphate pesticides considered the main option for a lot of people in many countries to manage different pests. It's more than 70 years now and OPs still use with certain purposes in gardens, fields and greenhouses as crop protection agents, or even at houses as public health agents. Thus, year after year and with the repeating usage of organophosphate agents many problems were appeared as a result to excessive use of pesticides. The adverse effects of pesticides usage represented in the effects on human health, environment, pesticides residue in crops and soil \& water contaminated by these pesticides. Therefore, it was necessary to throw a light on the risks that generated by irresponsible usage of organophosphate pesticides.
\end{abstract}

Keywords: Organophosphate Pesticides, Pesticide Toxicology, Human Health, Environment

\section{Introduction}

Organophosphorus or organophosphates (OPs) compounds are form the large groups of chemicals that used over the past 60 years for protecting crops, livestock, human health and as warfare agents. Organophosphates (OPs) are chemical substances originally produced by the reaction of alcohols and phosphoric acid. In the 1930s, organophosphates were used as insecticides, but the German military developed these substances as neurotoxins in World War II. They function as cholinesterase inhibitors, thereby affecting neuromuscular transmission. On the basis of structural characteristics they are divided into at least 13 types such as phosphates, phosphonates, phosphinates, phosphorothioates, phosphonothioates, phosphorodithioates, phosphorotrithioates, phosphoramidothioates (Gupta, 2006).

OPs are the most widely used pesticides worldwide and their metabolites are widespread across different populations (Aprea, 2000; Barr et al., 2004; Curl et al., 2003). The adverse short-term effects of exposure to these chemicals have been studied mostly in the nervous system, which is the main target (Gupta et al., 2001), but there is a growing concern about their possible toxic effects for nontarget tissues and (long-term) chronic effects that have not been studied in such detail. The majority of people are continually exposed to low OP concentrations, and long- term epidemiologic studies reveal linkage to higher risk of cancer development (Brown et al., 1990; Waddell et al., 2001).

Organophosphates effect on insects and mammals primarily by phosphorylation of the acetylcholinesterase enzyme (AChE) at nerve endings. Therefore, a loss in available AChE happened and the affected organ becomes over-stimulated by the excess acetylcholine (ACh, the impulse-transmitting substance) in the nerve ending. Some critical proportion of the tissue enzyme mass must be inactivated by phosphorylation before symptoms and signs of poisoning become manifest. At sufficient dosage, loss of enzyme function allows accumulation of Ach peripherally at cholinergic neuroeffector junctions (muscarinic effects), skeletal nerve-muscle junctions, and autonomic ganglia (nicotinic effects), as well as centrally (Routt and Roberts, 1999).

Certain reports were published in the last 30 years clarified that Pesticides especially Organophosphates group was responsible for admission millions of people to hospitals with accidental poisoning, in addition to suicidal cases. Meanwhile, it was estimated that about 25 million agricultural workers suffering from poisoning every year in the third world countries (Alavanja, 2009). Thus, this work aimed to make a small reminder about the risks of organophosphate pesticides. 


\section{The Impacts of Organophosphate Pesticides on Human Health}

\subsection{Cholinergic Effects}

The cholinergic effects brought about by repeated administration of less than a single fatal dose are similar in type to the acute single-dose effects (WHO,1986).

\subsection{Acute Toxicity}

Acute toxicity is the ability of a substance to cause harmful impacts soon after a single exposure or dose or any severe poisonous effect resulting from a single short-term exposure to a toxic substance. LD50 (lethal dose 50) is defined as the dose that kills $50 \%$ of a population of the tested animals (Ghosh and Philip, 2006), Profenofos is an insecticide, miticide and acaricide used only on cotton. In an acute study, neurotoxic signs were seen at $190 \mathrm{mg} / \mathrm{kg}$ in rats, and were more prominent in females. Also, in vitro studies have shown butyl cholinesterase to be more sensitive to profenofos inhibition than acetyl cholinesterase (AChE) (McDaniel and Moser, 2004)

\section{Chronic Toxicity}

Chronic toxicity is the capacity of a substance to cause long-term or delayed adverse health effects. Several reports proved the chronic toxicity of atrazine on various test organisms. After the sign of respiratory distress and paralysis of the limbs, $40 \%$ rats were died at an atrazine oral dose of $20 \mathrm{mg} / \mathrm{kg} /$ day for 6 months.

Body organs like brain, liver, kidneys, ovaries etc., were affected by organophosphates poisons and made structural and chemical changes, as well as growth retardation. In a study carried out for two years with dogs, results showed that $7.5 \mathrm{mg} \mathrm{kg}-1$ day-1 atrazine dose caused decreasing in food intake and increased heart and liver weights. The NOEL on rat was $70 \mathrm{mg} \mathrm{kg}-1$ whereas in dog it was $15 \mathrm{mg}$ kg-1 of body weight (Sameeh, 2004).

\section{Delayed Neuropathic Effects}

Delayed neuropathy has occurred occasionally in human being, livestock and experimental animals after intoxication with a variety of organophosphorus esters. However, many organophosphorus pesticides that might, theoretically, cause neuropathy, would only do so at a dose far above the lethal dose(WHO,1986).

\section{Mutagenic and Carcinogenic Effects}

Many Organophosphorus pesticides have not shown carcinogenic potential in animal experiments, but some pesticides do, through induction of tumors in rats and mice. No generalizations can be made due to some compounds exhibit mutagenic activity, whereas other compounds do not (WHO, 1986).

\section{Reproductive Effects}

A number of pesticides clearly have the potential to cause reproductive toxicity in animals, and several compounds e.g. (chlordecone ) are known to affect human reproduction (Sameeh, 2004). also OPs included insecticides (malathion, parathion, diazinon, fenthion, dichlorvos, chlorpyrifos, ethion), nerve gases (soman, sarin, tabun, VX), ophthalmic agents (echothiophate, isoflurophate), and antihelmintics (trichlorfon). Herbicides (tribufos [DEF], merphos) are tricresyl phosphatecontaining industrial chemicals.

\section{Immunotoxucity}

The scientific evidence suggesting that many pesticides damage the immune system. Animal studies have found that pesticides alter the immune system's normal structure, disturb immune responses, and reduce animal's resistance to antigens and infectious agents. In case of Malathion which is considered a very low toxic compound (oral LD50 $=2100 \mathrm{mg} / \mathrm{kg} \mathrm{bw}$ ), for example, not regulates the immune system, especially affecting non-specific immune mechanisms (Sameeh, 2004).

\section{Cytogenetic Effects}

Cytogenetic damage related to pesticides exposure has been reported in various populations. Some investigators have reported significant differences in the percentage of chromosomal aberrations (CAs) in exposed individuals (range, 2.66-10.30\%) compared with control (range, 0.53$5.52 \%$ ) (Sameeh, 2004).

\section{Cancer and Immunosuppression}

Studies showed that pesticide exposure significantly reduces resistance to bacterial, viral, and parasitic infections and promotes tumor growth in many animal species. People exposed to pesticides are at increased risk of contracting certain cancers known to be associated with immune suppression. In summary, pesticides could affect a variety of cancers through an immunological mechanism (Sameeh, 2004).

\section{Teratogenic Effects}

Detailed data on the effects of organophosphate occupational exposure on pregnant women and their fetuses are not available, although such information would be valuable. In humans only a few cases of acute organophosphorus insecticide poisoning during pregnancy have been described. A 24-year-old woman in her third month of pregnancy injected herself with Malathion in a 
suicide attempt. A therapeutic abortion was performed 2 months later. Continuation of the pregnancy was considered to be dangerous, although the condition of the fetus was not described (WHO,1986).

\section{Effects on the Immune System}

The most Organophosphorus pesticides elicit autoimmune reactions and suppress the production of antibodies against vaccines (Zackov, 1983).

\section{Effects on Tissue Carboxyesterase}

A variety of carboxyesterases abound in serum, liver, intestine and other tissues. Although inhibition of one specific carboxyesterase has toxic sequelae, but no direct deleterious effects of inhibiting other carboxyesterases have been demonstrated. Moreover, they may contribute markedly to the metabolic disposal of malathion and certain other organophosphorus pesticides, so that inhibition of tissue carboxyesterases may potentiate the toxicity of such pesticides (WHO,1986).

\section{Prophyric Effects}

Daily application of technical (85\%) diazinon (20 or 40 $\mathrm{mg} / \mathrm{kg}$ body weight) to the skin of Dark Agouti rats just above the tail produced a 4-fold increase in faecal porphyrins, after 8 - 12 weeks. However, they also found that Isodiazinon was very effective in causing porphyrin accumulation, when added to cultures of chick hepatocytes (WHO, 1986)

\section{Effects on Lipid Metabolism}

Organophosphate esters can inhibit the activities of some triglyceridases and lipases in vitro and in vivo (WHO,1986)

\section{References}

[1] Alavanja, M. C. (2009). Introduction: pesticides use and exposure extensive worldwide. Rev Environ Health. 24(4):303-309.

[2] Aprea, C.; Strambi, M.; Novelli, M.T.; Lunghini, L. and Bozzi, N. (2000). Biologic monitoring of exposure to organophosphorus pesticides in 195 Italian children. Environ Health Perspect. 108 (6): 521-5.

[3] Barr, D.B.; Bravo, R.; Weerasekera, G.; Caltabiano, L.M.; Whitehead, R.D. J.; Olsson, A.O.; Caudill, S.P.; Schober, S.E.; Pirkle, J.L. and Sampson, E.J. (2004). Concentrations of dialkyl phosphate metabolites of organophosphorus pesticides in the U.S. population. Environ Health Perspect, 112 (2):186-200.

[4] Brown, L.M.; Blair, A.; Gibson, R.; Everett, G.D.; Cantor, K.P.; Schuman, L.M.; Burmeister, L.F.; Van Lier, S.F. and Dick, F. (1990). Pesticide exposures and other agricultural risk factors for leukemia among men in Iowa and Minnesota. Cancer Res, 50 (20): 6585-91.

[5] Curl, C.L.; Fenske, R.A. and Elgethun, K. (2003). Organophosphorus pesticide exposure of urban and suburban preschool children with organic and conventional diets. Environ Health Perspe, 111 (3): 377-82.

[6] Ghosh P.K.; Philip L. (2006). Environmental Significance Of Atrazine In Aqueous Systems And Its Removal By Biological Processes: An Overview. Global NEST J, 8(2): 159-178.

[7] Gupta, R.C. (2006). Toxicology of Organophosphate \& Carbamate Compounds. Chapter 26, Elsevier Academic Press, Amsterdam, pp. 371-380.

[8] Gupta, S.; Stravitz, R.T.; Dent, P. and Hylemon, P.B. (2001) Down-regulation of cholesterol 7alpha-hydroxylase (CYP7A1) gene expression by bile acids in primary rat hepatocytes is mediated by the c-Jun N-terminal kinase pathway. J Biol Chem, 276 (19): 15816-22.

[9] Li, X., Jiang, J., Gu, L., Ali, S., He, J., Li, S. (2008). Diversity of chlorpyrifos-degrading bacteria isolated from chlorpyrifos-contaminated samples. International Biodeterioration and Biodegradation, 62, 331e 335

[10] McDaniel K. L.; Moser V. C. (2004). Differential profiles of cholinesterase inhibition and neurobehavioral effects in rats exposed to fenamiphos or profenofos, Neurotoxicol Teratol, 26: 407-415.

[11] Routt R. J., Roberts J. R. (1999). Recognition and management of pesticide poisonings.EPA, Washington DC., p. 223.

[12] Sameeh A. M. (2004). Pesticide exposure-Egyptian scene. Toxicol, 198: 91-115.

[13] Waddell, B.L.; Zahm, S.H.; Baris, D.; Weisenburger, D.D.; Holmes, F.; Burmeister, L.F.; Cantor, K.P. \& Blair, A. (2001) Agricultural use of organophosphate pesticides and the risk of non-Hodgkin's lymphoma among male farmers (United States). Cancer Causes Cont, 12 (6): 509-517.

[14] WHO (1986). Environmental Health Criteria 63. Organophosphorous Insecticides : a general introduction. World Health Organization, Geneva.

[15] Zakov K. (1983). Immunotoxicology of pesticides. In: Kalyanova F, Tarkowski S, eds. Toxicology of Pesticides Copenhagen. World Health Organization, Geneva; 75-88 (Health Aspects of Chemical Safety, Interim Document No. 9). 